\title{
MONITOX INTERNATIONAL NETWORK FOR MONITOR- ING OF ENVIRONMENTAL TOXICANTS AND RISK AS- SESSMENT IN THE BLACK SEA BASIN: RESEARCH AND INTERDISCIPLINARY COOPERATION DIMENSIONS
}

\author{
Antoaneta Ene ${ }^{1,2,}$ Elena Zubcov ${ }^{2,3}$, Thomas Spanos ${ }^{2,4}$, Oleg Bogdevich ${ }^{2,5}$, \\ Liliana Teodorof ${ }^{2,6}$ \\ 1"Dunarea de Jos" University of Galati, Faculty of Sciences and Environment, 47 Domneasca \\ Street, 800008 Galati, Romania, e-mail: aene@ugal.ro \\ ${ }^{2}$ INPOLDE interdisciplinary research network, Dunarea de Jos University of Galati, 111 Dom- \\ neasca St., Galati, Romania \\ ${ }^{3}$ Institute of Zoology, Chisinau, Republic of Moldova \\ ${ }^{4}$ International Hellenic University, Kavala, Greece \\ ${ }^{5}$ Institute of Geology and Seismology, Chisinau, Republic of Moldova \\ ${ }^{6}$ Danube Delta National Institute, 135 Babadag Street, Tulcea, Romania
}

\begin{abstract}
The paper presents the main tackled issues and results concerning the monitoring of the toxic substances (TOXs) in the network established in the frame of BSB27 MONITOX project, implemented by «Dunarea de Jos» University of Galati, Romania (Leader Partner) in partnership with Institute of Zoology, Republic of Moldova, International Hellenic University (IHU), Greece, Institute of Geology and Seismology, Republic of Moldova (IGS), and "Danube Delta" National Institute for Research and Development, Tulcea, Romania.

Maps of pollution of water, sediments, soils and biota with TOXs built using ArcGIS and Q-GIS highlight their levels and spatial-temporal distribution in the target zones in the three countries: Danube River (Lower sector), Prut and Dniester Rivers, Danube Delta, Black Sea coast, Nestos River and delta and Northern Aegean Sea coast.

The strategy designed and results of the interdisciplinary studies performed in the period 2018-2021 on a large range of toxic pollutants in the Black Sea Basin (including NE part of Greece) are emphasized, as well as the assessment of toxicants' impact upon human health using a health risk calculator developed as ICT tool.
\end{abstract}

\section{Introduction}

The migration of toxic chemicals (TOXs) with great impact on human health in the main aquatic ecosystems and protected areas from SE Romania, Republic of Moldova and Eastern Macedonia and Thrace, Greece, affects a large number of population of the sea basin and a very important issue for inhabitants of the large basin will be the identification of the sources of TOXs in their neighboring aquatic ecosystems and groundwater - agricultural terrains (fertilizers, pesticides), insufficient industrial and domestic wastewater treatment, erosion of polluted riparian soils, accumulations of municipal garbage and hazardous wastes, oil spills, vessel discharges, atmospheric depositions, release of toxics both from natural and anthropogenic sources (industry, traffic, animal farming, burning products, port and coastal activities, hospitals, nuclear activities) [1]. 
There is a need for high-quality monitoring data for the Black Sea Basin (BSB) and the European Union as a whole, along with ecotoxicological data and a thorough study of risks of environmental effects of TOXs. At basin level it was identified the necessity for establishing a new set of indicators to be used in various regions in monitoring of emerging toxic pollutants in water and related environmental matrices (sediment, biota), as well as the revising of the legislation regarding the thresholds of existing contaminant substances in these compartments, as a result of new scientific knowledge [2] and published literature data in international scientific journals.

There are some aspects which must be elucidated, related to: the real influence of the geological background on migration of some trace elements, metals and other compounds from the bedrock to sediments and surface water or ground water, the influence of river or sea on the quality of the groundwater, concentration of toxics preponderant in a matrix, the pollution of lands in the vicinity of rivers and seas with a large spectrum of TOXs which could spread on large distances in other compartments and could affect human health [1].

The main threat in the region is the immense deterioration perpetrated by human activities against the natural environment, which raises imperative concern for our collective survival. Pollution has no borders/does not stop at national borders. The in-depth study of processes occurring in large, interconnected river basins and evaluation of people exposure to TOXs can be accomplished only in partnership, through cooperation based on knowledge, exchange of good practices and interdisciplinary research, conducted only in transnational networks.

The project BSB27-MONITOX is aiming at enhancing regional cross-border cooperation in the Black Sea Basin (BSB) to improve joint monitoring of environmental toxic pollution and better share and exchange of new analysis methodology, data and information on ecological state and human health impact of harmful substances. This implies:

1) to build a strong BSB network of analytical laboratories and experts (MONITOX) to elaborate a common ecotoxicological monitoring system supporting regional programmes for environmental protection and sustainable management;

2) to produce a scientific platform with harmonized information on toxics in soil, water, sediments and biota in shared riverine, deltaic and sea areas, and their potential impact on ecosystems and people.

\section{Materials and methods}

The starting point of the project were the pressing issues signalled at European level, and the common challenges in the region jointly identified through analysing European legislation and EU Directives for environmental quality assessment; international conventions regarding the toxic chemicals and wastes (Minamata Convention on Mercury, Stockholm Convention on Persistent Organic Pollutants, Basel Convention on the Control of Transboundary Movements of Hazardous Wastes and their Disposal, Rotterdam Convention on the Prior Informed Consent Procedure for Certain Hazardous Chemicals and Pesticides in International Trade); Dan- 
ube and Black Sea Conventions; Convention on the Protection of the Black Sea Against Pollution; Convention Access to Information, Public Participation in Decision-making and Access to Justice in Environmental Matters (Aarhus); Convention on Environmental Impact Assessment in a transboundary context (Espoo); Convention on Wetlands of international importance (Ramsar); Convention on protection and use of transboundary water courses and international lakes (Helsinki); WHO and UNSCEAR regulations and recent scientific literature. Own experience gained in the frame of the previous implemented projects and from published research contributions of the five partners was valorized in the proposed activities and outputs $[1,3]$.

The project is implemented by "Dunarea de Jos" University of Galati, Romania (Leader Partner) in partnership with Institute of Zoology, Republic of Moldova, International Hellenic University (IHU), Greece, Institute of Geology and Seismology, Republic of Moldova (IGS), and "Danube Delta" National Institute for Research and Development, Tulcea, Romania.

The target zones in the three countries in BSB are: Danube River (Lower sector), Prut and Dniester Rivers, Danube Delta, Black Sea coast, Nestos River and its delta and Northern Aegean Sea coast.

The MONITOX international network strategy of monitoring of six classes of toxic substances in seven interconnected environmental compartments (surface water, groundwater, sediments, soils, bedrock and biota) in the Black Sea Basin and border regions, along with eight types of connected investigations (geomorphological, geological/mineralogical, hydrogeological, physical, chemical, biological, microbiological, ecotoxicological), along with mapping of BSB pollution, modelling of environmental processes and risk assessment is presented in Figure 1. Our pledge is: "Through collective action, environmental protection can be achieved" [3].

\section{MONITOX STRATEGY}

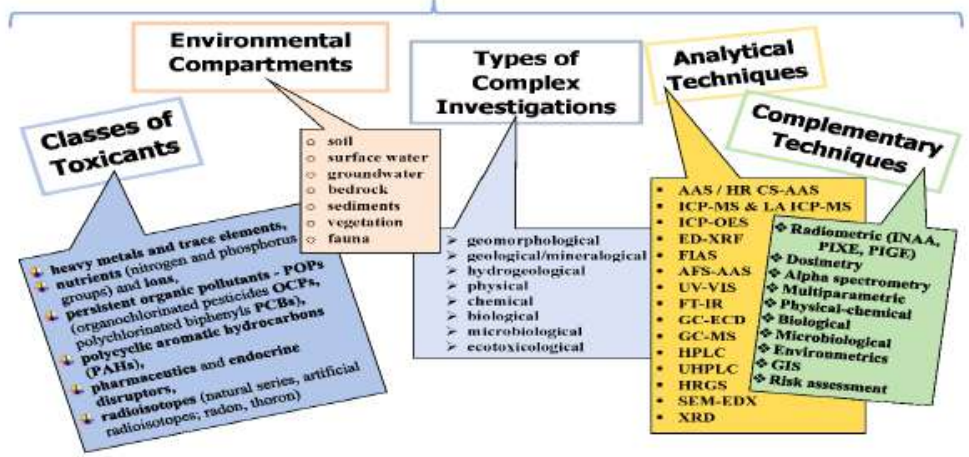

Figure 1. MONITOX international network investigation strategy

One of the project goals are the integration of the chemical, radioactivity, biological and microbiological measurements, in order to establish the surface water quality classes for the first time based on an integrated ecotoxicological quality index, with important impact on human health $[3,4]$. 
The analytical methods employed in partner institutions from Romania, Moldova, Greece and collaborating ones and used in complementarity for elemental and isotopic determination in sampled environmental materials (about 50 chemical elements), are the following: atomic absorption spectrometry (AAS), including High Resolution Continuum Source (HR CS-AAS) technique; inductively-coupled plasma mass spectrometry (ICP-MS) and laser ablation (LA) ICP-MS; inductively-coupled plasma optical emission spectrometry (ICP-OES); X-ray fluorescence analysis with energy dispersion (ED-XRF), including portable technique (p-XRF); high resolution low background gamma-ray Spectrometry (HRGS); instrumental neutron activation analysis (INAA) and ion beam techniques Particle-Induced X-ray (PIXE), Gamma-ray (PIGE) Emission using accelerated proton beams. Mercury is analyzed by flow injection for atomic spectrometry (FIAS) and a combination of fluorescence and absorbtion spectrometry (AFS-AAS). The accuracy and precision of the results are evaluated by measuring certified reference samples of similar matrix and organizing several intercomparison exercises between research laboratories [3,8]. More information is gathered for soil mineralogical constituents and microstructure using FT-IR, SEM, SEM-EDX and XRD complementary techniques.

Persistent organic pollutants (OCPs, PCBs) and pocyclic aromatic hydrocarbons (PAHs) are quantified by using gas-chromatography (GC-ECD, GC-MS) and liquid chromatography (HPLC) techniques. Moreover, oil pollutants (total petroleum hydrocarbons) in marine environment are investigated by FT-IR. UV-VIS is employed for nutrients and ions analysis in water samples, in connection with multiparametric and physical-chemical investigations.

The set of ecological indicators which are routinely monitored in the frame of national monitoring systems does not include yet the emerging toxicants, such as pharmaceutical residues and metabolites (antibiotics, anti-inflammatory, contraceptives), which are actually found in wastewater, surface water and groundwater. These are specified in EU-wide water monitoring Directive 2013/39/EU, which amended Water Framework Directive 2000/60/EC, and required a strategic approach to the pollution of water by pharmaceutical substances [1]. In the future the national monitoring systems at EU level will have to implement such indicators for emerging contaminants which might be appropriate for prioritization. Moreover, at Union level, it is foreseen to set environment quality standards (EQS) for newly identified substances, revising EQS for some existing substances in line with the scientific progress, and setting biota EQS for some pollutants [4]. An absolute novelty of investigations at maritime basin level is the adaptation and applying of Orbitrap UHPLC-MS for pharmaceuticals analysis in (Danube, Black Sea) surface water [9].

In May 2019 governments have amended the Basel Convention to include plastic waste in a legally-binding framework which will make global trade in plastic waste more transparent \& better regulated. Although microplastics were not included in the proposed list of monitored contaminants, research was carried out in the project on FT-IR identification of these polymeric materials in cosmetics, personal care and everyday use products.

Radiological maps and pollution maps of water, sediments and soils will be built using ArcGIS and Q-GIS [4]. 


\section{Results and discussions}

The planned objectives foresee complex investigations of the processes that take place in environmental compartments of aquatic ecosystems by assessing changes in chemical composition and water quality (physico-chemical, chemical, biological, microbiological parameters) in hydrographic basins of Danube, Prut, Dniester, Nestos and Black and Aegean Seas coastlines and assessment of the impact of TOXs on ecosystems state and human health.

To achieve these plans, joint complex expeditions in target aquatic ecosystems were organized, sampling and laboratory analytical techniques were adapted, optimized and harmonized between partners and modeling of processes and evaluation of ecological and health risks was carried out. Collection of environmetal data in the periods before and after COVID-19 pandemic allowed the comparison of ecological state and evaluation of anthropogenic impacts $[6,11,12]$.

Besides the novel implementation strategy, another specific objective of the BSB27 project is boosting awareness of the population in the Black Sea region on the environmental issues related to spread of toxicants by education and sharing scientific information and knowledge on health effects of inorganic, organic and radioactive pollutants. Dissemination of reliable, scientific information to various target groups is an important task of our project and is accomplished through ICT tools, including the assessment of toxicants impact upon human health, thus raising the level of awareness of the population in the Black Sea region regarding the environmental issues with cross-border impact: preservation of common natural resources and protected areas, prevention of spread of toxicants, hazardous waste disposal, changing behaviour on release of pollutants and reduce litter generation [5].

Digital maps of pollution, built using Q-GIS software, will be distributed through an IT platform created on the project website, together with scientific information regarding the impact of toxicants on population and aquatic ecosystems, possible sources in environment, modality of cross-border migration and accumulation in trophic chains in target areas of Black Sea region (rivers basin, deltas, sea littoral, marine environment), maximum allowed concentrations, and related legislation issues. The observed key patterns of elemental accumulation and migration in environmental compartments may be used in various environmental management programs and specific ecological studies in the Black Sea Basin.Through the created project social page on Facebook (fb.me/Monitox.project.BSB27), information on pollutants' spread in environment, their levels and danger to population (through ingestion, inhalation, dermal contact), carcinogenic effects, presence of microplastics in rivers, biota and personal care products, and good practices to reduce the impacts of TOXs upon health and ecological state are permanently distributed [5]. Innovative tools for the assessment of toxicants' impact upon human health and ecological state of aquatic ecosystems using a health risk calculator were developed. The health risk calculator (HRC) is designed as a webpage connected by a link to the project website. The HRC will also include a food toxicant calculator in order to evaluate the potential risk to human health of consumed fish or seafood, based on the estimate daily intake (EDI), the target hazard quotients (THQs), and carcinogenic risk ratio (R) as risk assessment elements [5]. A collection 
of digital materials in the form of a "Citizen's guide for evaluating exposure to toxicants" will be prepared for different categories of public. A great attention has to be payed to the analysis by dosimetry and alpha spectrometry of the gaseous radioactive isotopes, e.g. radon (222Rn and 220Rn) which represents the second factor of risk for population for pulmonary cancer, after smoking.

The project results were distributed by the organization of informational events (international conferences [7,10] and symposium [13], regional workshops, methodological seminars, webinars, expert trainings and practical activities in laboratories), publications in international journals and methodological guides. Their sustainability will be achieved through the elaboration and initiation of new projects at various national and international funds, preparation of scientific papers in open access journals, elaboration of laboratory guides and presentations for students courses on various topics tackled by the project.

The developed strategy, knowledge and common solutions for improved joint environmental monitoring in BSB will lead to:

- a better informing of various stakeholders on the existent levels of TOXs in the region,

- understanding of complex processes which take place during TOXs migration and accumulation in food chains,

- understanding the influence of toxicants and hazardous wastes on ecological state and human health.

Acknowledgements. The authors are thankful to the EU Black Sea Joint Operational Programme 2014-2020 for the funding of the project with eMS code eMS BSB 27 “ Black Sea Basin interdisciplinary cooperation network for sustainable joint monitoring of environmental toxicants migration, improved evaluation of ecological state and human health impact of harmful substances, and public exposure prevention - MONITOX'. The content of this publication is sole responsiblity of the authors and does not reflect the views of the European Union.

\section{Bibliography}

1. Ene A., Zubcov E., Spanos T., Bogdevich O., Teodorof L., Application form no. 027, 1st Call JOP Black Sea Basin 2014-2020, May 2017.

2. Ene A., Denga Y., Bogdevich O., Zubcov E. (Eds.): Atlas of Maps, Ed. Tehnopress, Iasi, 2015, ISBN 978-606-687-235-5, $40 \mathrm{p}$.

3. Ene A., Zubcov E., Spanos T., Bogdevich O., Teodorof L., MONITOX international network for monitoring of toxicants in the Black Sea Basin, International Conference "Environmental Toxicants in Freshwater and Marine Ecosystems in the Black Sea Basin”, September 8-11, 2020, Kavala, Greece, p.16.

4. Ene A., Zubcov E., Spanos T., Bogdevich O., Teodorof L., Interdisciplinary Cooperation for Ecological Monitoring in the Black Sea Basin, MONITOX International Symposium Deltas and Wetlands, September 15-17, 2019, Tulcea, Romania, p. 17-18.

5. Ene A., Zubcov E., Spanos T., Bogdevich O., Teodorof L., MONITOX health risk calculator and ICT tools for improved dissemination of scientific information in the Black Sea Basin, In- 
ternational Conference "Environmental Challenges in the Black Sea Basin: Impact on Human Health" Galati, Romania, 23rd $\div$ 26th September, 2020, p. 42-43.

6. Ene A., Vasile M.A., Bahrim G., Study of microbiological contamination level of surface water in MONITOX network areas before and after COVID-19 pandemic, Annals Dunarea de Jos Univ. Galati, Fasc. II. Math Phys Theor Mech 43(2) (2020) 75-81.

7. Ene A., Teodorof, L., (Eds.): Abstract Book, International Conference "Environmental Challenges in the Black Sea Basin: Impact on Human Health" Galati, Romania, 23rd $\div 26$ th September, 2020, Editura Casa Cartii de Stiinta. Cluj Napoca, 50 p.

8. Ene A., Pantelică A., Stihi C., Frontasyeva M., Bogdevich O., Culighin E. et al., Development of analysis methodology using Proton Induced X-ray Emission (PIXE) as a complementary technique to determine trace elements in environmental matrices, Annals Dunarea de Jos Univ. Galati, Fasc. II. Math Phys Theor Mech 42(2) (2019) 117-125.

9. Enachi E., Bahrim G. E., Antoaneta Ene, Pharmaceutical compounds and endocrine disruptors in aquatic environments: ecotoxicological effects and analysis methodology, Annals Dunarea de Jos Univ. Galati, Fasc. II. Math Phys Theor Mech 42(2) (2019) 172-182.

10. Spanos T., Ene A., Iakovoglou V. (Eds.), Abstract Book, International Conference "Environmental Toxicants in Freshwater and Marine Ecosystems in the Black Sea Basin", September 8-11, 2020, Kavala, Greece, OrganotikiOE, ISBN 978-618-85036-0-1, 100 pp.

11. Spiridon C., Burada A., Teodorof L., Despina C., Seceleanu- Odor D., Tudor M., Ene, A., Chlorophyll a and total nutrients distribution from surface waters in Romanian MONITOX network in 2019 and 2020, Annals Dunarea de Jos Univ. Galati, Fasc. II. Math Phys Theor Mech 43(2) (2020) 184-189.

12. Teodorof L., Burada A., Despina C., Seceleanu-Odor D., Spiridon C., Tiganus M., Tudor I.-M., Tudor M., Ene A., Zubcov E., Spanos T., Bogdevich O., Sediments quality assessment in terms of single and integrated indices from Romanian MONITOX network (2019 - 2020), Annals Dunarea de Jos Univ. Galati, Fasc. II. Math Phys Theor Mech 43(2) (2020) 175-183.Teodorof L., Ene A., Zubcov E., Spanos T., Bogdevich O. (Eds.): Abstract Book, MONITOX International Symposium Deltas and Wetlands, September 15-17, 2019, Tulcea, Romania, 2019, C.I.T.D.D. Tulcea. 